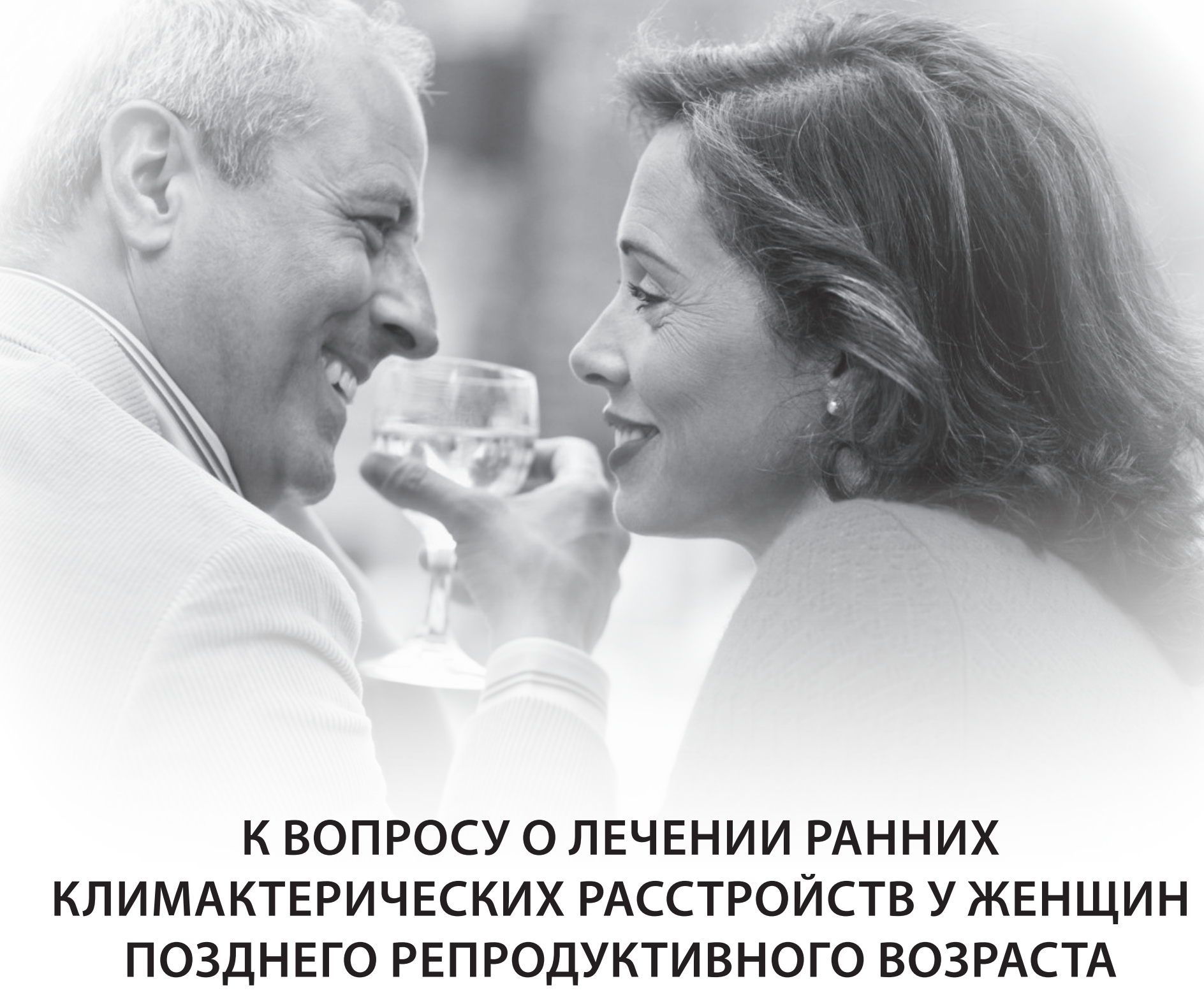

\section{Т.Ф. ТАТАРЧУК}

д. мед. н., профессор,

член-корр. НАМН Украины, заместитель директора по научной работе,

заведующая отделением эндокринной гинекологии Института педиатрии, акушерства и гинекологии НАМН Украины

O.А. ЕФИМЕНКО

к. мед. н., старший научный сотрудник отделения эндокринной гинекологии Института педиатрии, акушерства и гинекологии НАМН Украины

\section{A.O. ИСЛАМОВА}

к. мед. н., отделение эндокринной гинекологии Института педиатрии, акушерства и гинекологии НАМН Украины

\author{
ВВЕДЕНИЕ \\ Несмотря на значительное количество \\ исследований, посвященных здоровью \\ женщин старше 50 лет, проблема лечения \\ климактерических расстройств и сегодня \\ чрезвычайно актуальна, потому что касается \\ в первую очередь качества жизни женщин в \\ периоде их профессиональной зрелости и \\ наибольшей востребованности в обществе и \\ семье. Увеличение продолжительности жиз- \\ ни и продление возраста трудоспособности \\ приобретает не только медицинское, но и со- \\ циально-экономическое значение как в на- \\ шей стране, так и в других развитых странах. \\ По прогнозам ВО3, к 2015 году 46\% женщин \\ на планете будут в возрасте старше 45 лет \\ (в пери- и постменопаузальном периодах), \\ среди женщин Украины это почти половина \\ $(13,2$ млн) $[3,4,6]$. \\ Хочется отметить, что именно переход- \\ ный период перед менопаузой является \\ этапом наибольшей социальной актив- \\ ности современной женщины. Поэтому \\ проблемы внешности и здоровья, наличия \\ жизненных сил и отсутствия менопаузаль- \\ ных нарушений становятся все более зна- \\ чимыми и требуют грамотного медицин- \\ ского сопровождения.
}

\section{АНАЛИЗ ЛИТЕРАТУРНЫХ ДАННЫХ И ПОСТАНОВКА ЗАДАЧИ ИССЛЕДОВАНИЯ}

Общеизвестно, что именно дефицит эстрогенов в перименопаузе приводит к возникновению различных вегетативных и психоэмоциональных симптомов, таких как приливы, колебания настроения, раздражительность, бессонница, снижение когнитивных функций $[3,6]$.

Согласно современным представлениям, именно заместительная гормональная терапия (ЗГТ) остается главным патогенетически обоснованным медикаментозным методом лечения. Однако, несмотря на высокую эффективность применяемых лекарственных средств, многие женщины отказываются от гормональной терапии из-за не совсем обоснованной онкофобии или нарушают режим приема препарата, что, согласно современным представлениям, недопустимо. По данным Европейского исследования, у 23\% женщин продолжительность 3ГТ не превысила 1 года, 41\% женщин использовали ЗГТ в течение 1-5 лет, 20\% - в течение 6-10 лет и 16\% - более 10 лет [1, 3]. Вместе с тем, очевидно, что кратковременная терапия не позволяет полностью реализовать весь потенциал действия гор- 
монов и, что важно, достичь отдаленных профилактических эффектов. Поэтому повышение приемлемости терапии является важнейшим условием ее максимальной эффективности.

Однако, учитывая противопоказания для назначения ЗГТ или нежелание женщины принимать гормональные препараты, перспективным направлением медикаментозной терапии климактерических расстройств является использование веществ, обладающих SERM-эффектом (селективных модуляторов эстрогенных рецепторов). Эти вещества не влияют на а-рецепторы молочных желез и эндометрия. Эффект селективных модуляторов обусловлен их тропностью к эстрогенным $\beta$-рецепторам, локализованным преимущественно в костной ткани, сосудах, центральной нервной системе. При назначении данных препаратов риск развития рака молочной железы значительно снижен. Использование селективных модуляторов эстрогенных рецепторов позволяет не назначать гестагены в случае интактной матки, что также увеличивает онкопротекторный эффект: в некоторой степени снижает возможные неблагоприятные влияния на морфофункциональное состояние молочных желез $[2,5]$.

Одним из таких препаратов является Сагенит, химическая структура - мезодиэтилэтилендибензолсульфоната дикалия дигидрат (рисунок 1).

Установлено, что Сагенит можно рассматривать как своеобразный селективный модулятор эстрогенных рецепторов, оказывающий как периферическое антиэстрогенное действие на репродуктивные органы, так и центральное ингибирующее действие на гипоталамо-гипофизарную систему, тем самым способствуя торможению синтеза гонадотропных гормонов, ответственных за рост и созревание фолликулов в яичнике. При этом отмечается эстрогеноподобное действие на метаболизм липидов и углеводов, что, видимо, обусловлено стероидной структурой сигетина (производного дифенилгексана).

Целью работы было изучение эффективности и безопасности препарата Сагенит у пациенток с климактерическими расстройствами легкой и средней степени тяжести в позднем репродуктивном периоде.

\section{МАТЕРИАЛЫ}

\section{И МЕТОДЫ ИССЛЕДОВАНИЯ}

Под наблюдением находилось 50 пациенток в возрасте 37-49 лет (средний возраст 43,4 \pm 0,7 лет) с климактерическими расстройствами легкой и средней степени тяжести. Всем обследованным проводились диагностика климактерических расстройств (согласно менопаузальной рейтинговой шка- ле MRS) до и после лечения, определение радиоиммунологическим методом уровня фолликулистимулирующего (ФСГ) и лютеинизирующего (ЛГ) гормонов, эстрадиола, пролактина до и после лечения, УЗИ органов малого таза (УЗИ проводили трижды: на этапе скрининга, спустя 1 и 3 месяца после окончания терапии препаратом Сагенит с целью контроля безопасности эндометрия), УЗИ щитовидной и молочных желез в динамике до и после лечения. Полученные результаты обработаны методом параметрической статистики, адаптированной для медико-биологических исследований.

Критериями включения были клинически и лабораторно подтвержденные климактерические расстройства легкой и средней степени тяжести у женщин позднего репродуктивного возраста, критериями исключения: активные воспалительные заболевания органов малого таза, опухоли и гиперпластические процессы органов малого таза, эндо-

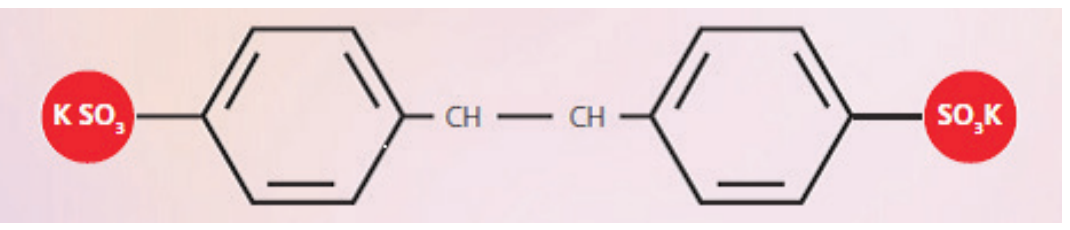

метриоз, опухоли гипофиза, надпочечников, адреногенитальный синдром, беременность, лактация, хронические соматические заболеРИСУНОК 1. СТРУКТУРНАЯ ФОРМУЛА САГЕНИТА вания (печеночная и/или почечная недостаточность), системные заболевания.

\section{ТАБЛИЦА 1}

1. Приливы (усиливающееся чувство жара, внезапные приступы потливости)

2. Жалобы со стороны сердечно-сосудистой системы (сердцебиение, тахикардия, аритмия, чувство сжатия сердца)

3. Нарушения сна (проблемы с засыпанием, тревожный сон, слишком раннее пробуждение, бессонница) 4. Жалобы на боли в суставах и мышцах (боли в области суставов, ревматические боли)

5. Депрессивные настроения (уныние, грусть, плаксивость, апатичность, резкие перепады настроения) 6. Раздражительность (нервозность, внутреннее напряжение, агрессивность)

7. Боязливость (внутреннее беспокойство, паника)

8. Физическое и духовное истощение (общее снижение работоспособности, пониженная умственная деятельность, слабая концентрация, забывчивость)

9. Сексуальные проблемы (изменение сексуального желания, поведения и удовлетворения)

10. Нарушения мочеиспускания (болезненное мочеиспускание, частое мочеиспускание, непроизвольное мочеиспускание)

11. Сухость влагалища (ощущение сухости или жжения во влагалище, болезненность при половых контактах)

Оценка клинических особенностей течения климактерического синдрома у исследуемого контингента женщин проводилась с использованием менопаузальной рейтинговой шкалы (MRS) до лечения, а также через 1 и 3 месяца применения терапии [6, 7]. После компьютерной обработки данных, полученных при заполнении специальной анкеты (таблица 1),
ТАБЛИЦА 1. МЕНОПАУЗАЛЬНАЯ РЕЙТИНГОВАЯ ШКАЛА (MRS)* * степень выраженности каждого клинического проявления оценивается по 5-балльной шкале: отсутствует (0), слегка выражено

(1), умеренно (2), сильно (3) и очень сильно (4) 


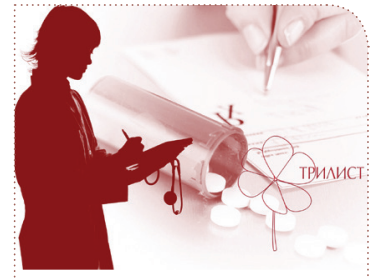

Проведенное исследование показало, что высокий уровень безопасности и эффективности препарата Сагенит дает возможность использовать его при ранних проявлениях климактерических расстройств у женщин в постменопаузе

учитывающей клинические проявления климактерических нарушений с балльной оценкой степени выраженности патологии, вычислялся суммарный индекс менопаузы.

Препарат Сагенит назначался в дозе 2 таблетки в сутки на протяжении 30 дней.

\section{РЕЗУЛЬТАТЫ ИССЛЕДОВАНИЯ И ИХ ОБСУЖДЕНИЕ}

Динамика климактерических жалоб, согласно шкале MRS, отображена на рисунке 2. После проведенной терапии средний менопаузальный индекс, согласно шкале MRS, был достоверно ниже, чем до начала терапии. Так, 28 пациенток отметили полное отсутствие перименопаузальных симптомов после 30 дней приема Сагенита. Практически все женщины отметили уменьшение количества приливов,

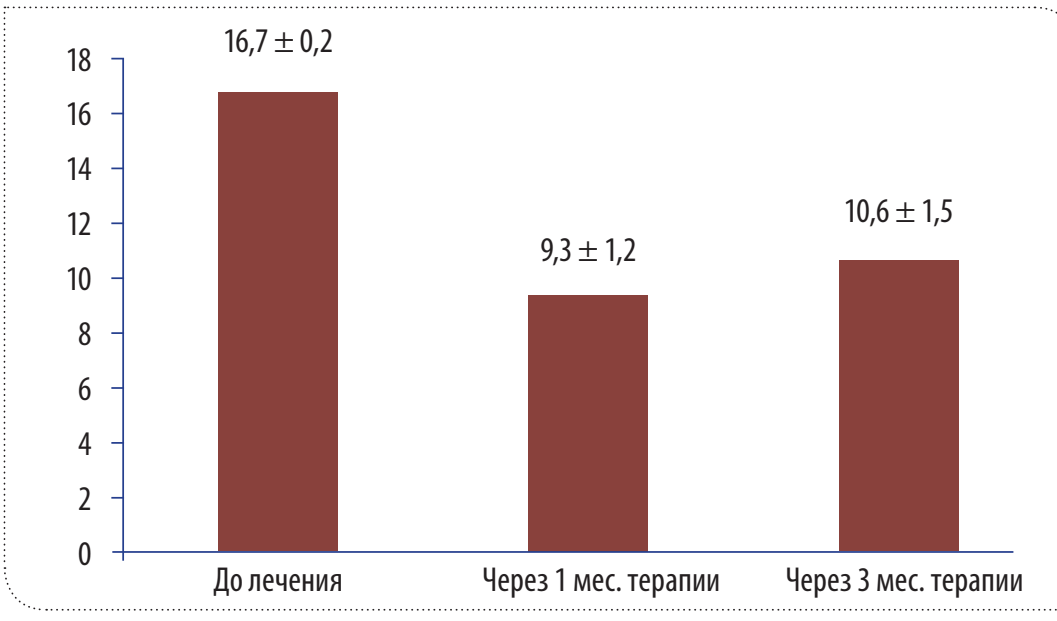

РИСУНОК 2. ДИНАМИКА

КЛИМАКТЕРИЧЕСКИХ РАССТРОЙСТВ ДО И ПОСЛЕ ЛЕЧЕНИЯ (ПО ШКАЛЕ MRS)

улучшение настроения, нормализацию сна, повышение работоспособности, улучшение памяти. В большей степени препарат Сагенит влиял на нейровегетативные и психоэмоциональные симптомы, которые в процессе лечения значительно уменьшились, а обменно-эндокринные симптомы практически не изменились.

\section{ТАБЛИЦА 2}

\section{На этапе скрининга}

10,1

ТАБЛИЦА 2. ДИНАМИКА ТОЛЩИНЫ ЭНДОМЕТРИЯ У ЖЕНЩИН НА ФОНЕ ПРИЕМА САГЕНИТА (ЛЮТЕИНОВАЯ ФАЗА)

* достоверных изменений не выявлено
Средняя толщина эндометрия, мм

Через 1 мес. лечения

10,9

Через 3 мес. лечения 11,2

Сагенит оказался высокоэффективным при наличии «классических» эстрогендефицитных проявлений - приливов и потливости. Значительное уменьшение проявления данных симптомов наблюдалось к окончанию 30-дневной терапии данным препаратом. Следует отметить, что и через 3 месяца после проведенного лечения индекс шкалы MRS оставался ниже, чем до использования препарата Сагенит.

Что касается гормонального гомеостаза, то у всех обследованных женщин уровни гормонов соответствовали перименопаузальным значениям. Результаты сравнительного анализа показали, что до лечения уровни эстрадиола плазмы крови у женщин были снижен- ными (59,3 — 1,3 пмоль/л), что свидетельствует о прогрессировании эстрогеноподобного дефицита. Спустя месяц наблюдения уровень эстрогенов практически не изменился, но и не снизился, оставаясь 57,3 \pm 1,1 пмоль/л. Препарат Сагенит не оказывал эстрогеноподобного действия, но способствовал стабилизации уровня эстрадиола.

Уровень пролактина также не изменился после проведенной терапии, оставаясь в пределах нормальных референтных значений (соответственно 15,4 \pm 1,3 и 19,2 \pm 1,7 мME/л).

Концентрации ФСГ и ЛГ в плазме крови до лечения были несколько повышены: ФСГ составлял 36,5 \pm 1,1 ME/л и ЛГ - 27,2 \pm 1,7 ME/л. Через один месяц лечения лабораторные исследования показали тенденцию к нормализации изучаемых показателей у женщин (ФСГ до 28,9 \pm 1,1 ME/л, ЛГ - до 21,7 \pm 1,5 ME/л). Полученные результаты отражают способность Сагенита несколько корректировать повышенные значения гонадотропных гормонов уже после 30 дней приема препарата, данный феномен объясняется способностью Сагенита участвовать в реализации положительной и отрицательной обратной связи в гипотоламо-гипофизарно-яичниковой системе, оказывать стабилизирующее действие на гонадотропную функцию гипофиза и гипоталамический центр.

Влияние Сагенита на толщину эндометрия можно в целом назвать нейтральным. Так, у всех 50 женщин, по данным УЗИ, во вторую фазу менструального цикла не отмечался рост эндометрия (через 1 и 3 мес. после окончания терапии), что подтверждает SERMэффект Сагенита (таблица 2).

Ультрасонографических изменений в молочных и щитовидной железах после окончания терапии Сагенитом не наблюдалось.

В ходе проведенного наблюдения за пациентками побочных эффектов и реакций индивидуальной непереносимости отмечено не было. Следовательно, высокий уровень безопасности и эффективности препарата Сагенит дает возможность использовать его при ранних проявлениях климактерических расстройств у женщин в позднем репродуктивном периоде (в перименопаузе).

\section{ВЫВОд}

Таким образом, полученные результаты исследования доказывают целесообразность использования препарата Сагенит у женщин позднего репродуктивного возраста с целью коррекции климактерических расстройств легкой и средней степени тяжести, учитывая его хорошую клиническую эффективность, отсутствие влияния на эндометрий, молочные и щитовидную железы, хорошую переносимость и удобство применения. 


\section{ЛИТЕPATYPA/REFERENCES}

\section{1. Андреева Е.Н.}

Эффективность и переносимость препаратов для терапии климактерических расстройств // Гинекология. - 2005. - № 2. - С. 109-110.

\section{Andreeva, E.N.}

"Efficacy and tolerability of drugs for the treatment of menopausal disorders.» Gynecology, 2(2005):109-110.

2. Грищенко О.В., Лахно И.В.

Репродуктивная эндокринология. - 2013. - № 5(13). - С. 70-73.

Grishchenko, O.V. Lakhno, I.V.

«Reproductive Endocrinology.» 5(13) (2013):70-73.

3. Медицина климактерия // Под ред. В.П. Сметник. - М., - 2006. - 848 с. Smetnik, V.P.

«Medicine menopause.» M. (2006) 848 p.

\section{4. Татарчук Т.Ф., Єфіменко О.А.}

Принципи діагностики, профілактики та лікування клімактеричних розладів // Журнал української лікарської еліти. - № 4(10). - 2009. - С. $24-29$.

Tatarchuk, T.F. Efimenko, O.A.

«Principles of diagnosis, prevention and treatment of menopausal disorders.» Journal of Ukrainian Medical Elite, 4(10) (2009):24-29.

5. Cleve, A. Fritzemeier, K.H, Haendler, B. et al.

«Pharmacology and clinical use of sex steroid hormone receptor modulators.» Handb Exp Pharmacol, 214(2012):543-587.

6. Menopuse State of the art / ed. Iole Di Francesco (2011) $540 \mathrm{p}$.

7. Scheider, H.P.G. Heinemann, L.A.J. Rosemeir, H.P. et al. «The menopause rating scale (MRS): reliability of scores of menopausal compleants.» Climacteric, 3(2000):59-64.

\section{ЩОДО ПИТАННЯ ЛІКУВАННЯ РАННІХ КЛІМАКТЕРИЧНИХ РОЗЛАДІВ У ЖІНОК ПІЗНЬОГО РЕПРОДУКТИВНОГО ВІКУ}

Т.Ф. Татарчук, д. мед. н., професор, член-кор. НАМН України, заступник директора з наукової роботи, завідуюча відділенням ендокринної гінекології Інституту педіатрії, акушерства та гінекології НАМН України

0.А. Єфіменко, к. мед. н., старший науковий співробітник відділення ендокринної гінекології Інституту педіатрії, акушерства та гінекології НАМН україни

А.О. Ісламова, к. мед. н., відділення ендокринної гінекології Інституту педіатрії, акушерства та гінекології НАМН України

Проведено дослідження препарату Сагеніт у жінок пізнього репродуктивного віку з клімактеричним синдромом. Під наглядом перебувало 50 пацієнток віком 37-49 років з клімактеричними розладами легкого та середнього ступенів тяжкості. Лікування проводили протягом 1 місяця. Ефективність препарату оцінювали через 1 і 3 місяці після терапії.

Сагеніт виявився високоефективним в лікуванні «класичних» естрогендефіцитних проявів (припливи і пітливість), а також в усуненні нейровегетативних та психоемоційних симптомів.

У ході проведеного спостереження за пацієнтками побічних ефектів і реакцій індивідуальної непереносимості відзначено не було.

Отримані результати дослідження доводять доцільність використання препарату Сагеніт у жінок пізнього репродуктивного віку $з$ метою корекції клімактеричних розладів легкого та середнього ступенів тяжкості.

Ключові слова: замісна гормональна терапія, клімактеричний синдром, Сагеніт.

\section{TO A QUESTION OF MENOPAUSAL DISORDERS TREATMENT IN WOMEN OF THE LATE REPRODUCTIVE AGE}

T.F. Tatarchuk, MD, professor, corresponding member of NAMS of Ukraine, Deputy Director for Research Work, Chief of the Endocrine Gynecology Department, Institute of Pediatrics, Obstetrics and Gynecology, NAMS of Ukraine

O.A. Yefimenko, PhD, senior researcher of the Endocrine Gynecology Department, Institute of Pediatrics, Obstetrics and Gynecology NAMS of Ukraine

A.0. Islamova, PhD, Endocrine Gynecology Department, Institute of Pediatrics, Obstetrics and Gynecology NAMS of Ukraine

A study of using the drug Sagenit in women reproductive age with climacteric syndrome was done. We observed 50 patients aged 37-49 years with climacteric disorders mild to moderate severity. Treatment lasts for a one month. Effectiveness of the drug was evaluated at 1 and 3 months after treatment. Sagenit proved highly effective in the treatment of «classical» estrogen deficiency manifestations (sweating and hot flushes), as well as in elimination of neurovegetative and psycho-emotional symptoms.

There were not observed side effects and reactions of individual intolerance during monitoring of patients.

The obtained results of the study demonstrate the feasibility of using the drug Sagenit in women reproductive age in order to correct menopausal disorders mild to moderate severity.

Key words: hormone replacement therapy, menopause, Sagenit. 